risk of death associated with it was high. It was also the commonest single recorded reason for emergency readmissions. Recently it has been emphasised that early mobilisation after hip replacement reduces the incidence of postoperative thromboembolic disease. ${ }^{21}$ Investigation of the possibility of further reduction in postoperative deaths from circulatory disease in general, and perhaps thromboembolic disease in particular, is warranted.

The unit of clinical epidemiology is part of the department of public health and primary care at the University of Oxford and is funded by the Department of Health. The Oxford record linkage study is funded by Oxford Regional Health Authority. We thank Hugh Simmons and Margaret Godden for extracting data from the Oxford record linkage study files, Kate Hey for drawing the original figures, and Pamela Evans and Penny Buddenhagen for typing the manuscript.

1 Wroblewski BM. Charnley low-friction arthroplasty. Review of the past, present status, and prospects for the future. Clin Orthop 1986;201;:37-42.

2 Cornell CN, Ranawat CS. Survivorship analysis of total hip replacements. Results in a series of active patients who were less than fifty five years old. f Bone foint Surg [Am] 1986;68:1430-4.

3 Gustilo RB, Burnham WH. Long-term results of total hip arthroplasty in young patients. In: Nelson JP, ed. The hip. Proceedings of the tenth open young patients. In: Nelson JP, ed. The hip. Proceedings of the tenth
scientific meeting of the Hip Society. St Louis: CV Mosby, 1982:27-33.

4 Terayama K. Experience with Charnley low-friction arthroplasty in Japan. Clin Orthop 1986;211:79-84.

5 Wroblewski BM. 15-21-year results of the Charnley low-friction arthroplasty Clin Orthop 1986;211:30-5.
6 Chandler HP, Reineck FT, Wixson RL, McCarthy JC. Total hip replacement in patients younger than thirty years old. A five year follow-up study. 7 Bone in patients younger than thirty yeas
foint Surg $[A m] 1981 ; 63: 1426-34$.

7 Dorr LD, Takei GP, Conaty JP. Total hip arthroplasty in patients less than forty-five years old. F Bone foint Surg (Am) 1983;65: 474-9.

8 Ranawat CS, Atkinson RE, Salvati EA, Wilson PD. Conventional total hip arthroplasty for degenerative joint disease in patients between the ages of forty and sixty years. F Bone foint Surg [Am] 1984;66:745-52.

9 Welch RB, McGann WA, Picetti GD. Charnley low-friction arthroplasty. A fifteen to seventeen year follow-up study. Orthop Clin North Am 1988;19: 551-5.

10 Brady LP, McCutchen JW. A ten-year follow-up study of 170 Charnley total hip arthroplasties. Clin Orthop 1986;211:51-4.

1 Charnley J. Fracture of femoral prostheses in total hip replacement. A clinical study. Clin Orthop 1975;111:105-20.

12 Older J. Low-friction arthroplasty of the hip. A 10-12-year follow-up study Clin Orthop 1986;211:36-42.

13 Salvati EA, Wilson PD, Jolley MN, Vakili F, Aglietti F, Brown GC. A ten year follow up-study of our first one-hundred consecutive Charnley total hip replacements. F Bone foint Surg [Am] 1981;62:753-67.

14 Department of Health and Social Security. Hospital In-patient Enquiry. London: HMSO. (Annual from 1955 to 1985 .)

15 Frankel W, Williams M, Nanchahal K, Coast J. Total hip and knee joint ڤొ replacement. Bristol: University of Bristol, 1991. (DHA project, report 2.) 6 Classification of surgical operations. 3rd Revision. London: Office of Population Censuses and Surveys, 1975

17 Henderson J, Goldacre MJ, Graveney MJ, Simmons HM. Use of medical records linkage to study readmission rates. BMF 1989;299:709-13.

18 Baker RJ, Nelder JA. The GLIM system release 3. Oxford: Numerical Algorithms Group, 1978.

19 Nicholl JP, Thomas KJ, Williams BT, Knowelden J. Contribution of the private sector to elective surgery in England and Wales. Lancet 1984;ii:

20 Nicholl JP, Beeby NR, Williams BT. Role of private sector in elective surgery in England and Wales, 1986. BMf 1989;298:243-7.

21 Lassen MR, Borris LC. Mobilisation after hip surgery and efficacy of $\vec{G}$ thromboprophylaxis. Lancet 1991;337:618.

(Accepted 25 September 1991 )

\title{
Cost effectiveness of magnetic resonance imaging in the neurosciences
}

\author{
A K Szczepura, J Fletcher, J D Fitz-Patrick
}

\begin{abstract}
Objectives-To measure, in a service setting, the effect of magnetic resonance imaging on diagnosis, diagnostic certainty, and patient management in the neurosciences; to measure the cost per patient scanned; to estimate the marginal cost of imaging and compare this with its diagnostic impact; to measure changes in patients' quality of life; and to record the diagnostic pathway leading to magnetic resonance imaging.
\end{abstract}

Design-Controlled observational study using questionnaires on diagnosis and patient management before and after imaging. Detailed costing study. Quality of life questionnaires at the time of imaging and six months later. Diagnostic pathways extracted from medical records for a representative sample.

Setting-Regional superconducting $1.5 \quad T$ magnetic resonance service.

Subjects -782 consecutive neuroscience patients referred by consultants for magnetic resonance imaging during June 1988-9; diagnostic pathways recorded for 158 cases.

Main outcome measures-Costs of magnetic resonance imaging and preliminary investigations; changes in planned management and resulting savings; changes in principal diagnosis and diagnostic certainty; changes in patients' quality of life.

Results-Average cost of magnetic resonance imaging was estimated at $£ 206.20$ /patient (throughput 2250 patients/year, 1989-90 prices including contrast and upgrading). Before magnetic resonance imaging diagnostic procedures cost $£ 164.40 /$ patient (including inpatient stays). Management changed after imaging in $208(27 \%)$ cases; saving an estimated $£ 80.90$ /patient. Confidence in planned management increased in a further $226(29 \%)$.referrals. Consult- ants' principal diagnosis changed in 159 of $782(20 \%)$ referrals; marginal cost per diagnostic change was £626. Confidence in diagnosis increased in $236(30 \%)$ referrals. No improvement in patients' quality of life 0 at six month assessment.

Conclusions - Any improvement in diagnosis with magnetic resonance imaging is achieved at a higher cost. Techniques for monitoring the cost effectiveness of this technology need to be developed.

\section{Introduction}

Magnetic resonance imaging is recognised as a potentially useful,,$^{1-6}$ although expensive, ${ }^{7-9}$ imaging technique. Early evaluations of its clinical benefits

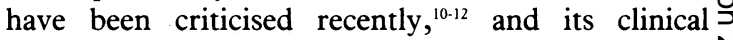
efficacy still has to be rigorously shown. ${ }^{13-16}$ Mean- $N$ while, clinicians and managers are faced with decisions $D$ on when and how to introduce this new medical technology. ${ }^{17}$

In 1988 the West Midlands region opened its first N magnetic resonance imaging service, based in 0 Coventry. It was expected that the main user would be the neurosciences, ${ }^{418-20}$ and that demand would outstrip supply. Therefore, population based quotas were $\cong$ allocated to each of the region's four neuroscience 0 centres. In addition, a service evaluation was commissioned to measure the extent to which magnetic $\mathbb{\mathbb { D }}$ resonance imaging in routine neuroscience clinical $\Phi$ practice is worth its costs. As a result a large database $\frac{O}{O}$ has been built up and a full analysis is available elsewhere. ${ }^{21}$ This paper presents some of the findings $\delta$ of the study.

\section{Methods}

After a three month learning period we entered into the study all 782 patients scanned by the service as part 
of the NHS quota during the service's first year of operation. The imager is superconducting and runs at $1.5 \mathrm{~T}$.

\section{COSTS OF SCANNING}

At the end of the first year we undertook a detailed study of costs, examining staff, consumables, capital, maintenance, and indirect costs. Staffing costs included employer's costs (national insurance, superannuation, etc) as well as basic salary or wage costs. In the case of radiologists an additional sum representing a regional average for merit awards, travelling expenses, domiciliary visits, etc was added. Consumable costs included cryogens, electricity, films, film processing chemicals, stationery, computer tapes, and replacement parts. Capital costs were calculated using the annuity method. ${ }^{17}$ The economic life of the imaging system was assumed to be seven years (other studies have used lifetimes ranging from five to seven years). ${ }^{91522}$ A 25 year life was used for accommodation, rather than the more usual NHS value of 40 years, because of its specialised nature; other studies have used lifetimes of 10-25 years. ${ }^{9}{ }^{150}$ Once global annual expenditure had been calculated, costs were divided equally between all referrals to produce an average cost per patient scanned.

\section{EFFECTS OF MAGNETIC RESONANCE IMAGING}

We used a controlled observational study to measure the impact of magnetic resonance imaging. This technique requires clinicians to specify their differential diagnosis and treatment plan before and after an investigation, thereby reducing the bias produced by retrospective evaluation. ${ }^{23}$ All patients were referred by a consultant. For each referral consultants completed a structured request form detailing the probable site of lesion, category of diagnosis (up to three differential diagnoses with level of certainty $(0-100 \%$ on a linear scale)), further investigations or treatment

TABLE I-Number (percentage) of neuroscience patients scanned by magnetic resonance imaging for two main specialtiest

\begin{tabular}{lcc}
\hline & \multicolumn{2}{c}{ Specialty } \\
\cline { 2 - 3 } Anatomical region & $\begin{array}{c}\text { Neurology } \\
(\mathrm{n}=437)\end{array}$ & $\begin{array}{c}\text { Neurosurgery } \\
(\mathrm{n}=320)\end{array}$ \\
\hline Brain & $327(75)$ & $113(35)$ \\
Pituitary fossa & $4(1)$ & $1(<1)$ \\
Brain and spine & $48(11)$ & $36(11)$ \\
Cervical spine & $26(6)$ & $78(24)$ \\
Dorsal spine & $1(<1)$ & \\
Lumbar spine & $13(3)$ & $52(16)$ \\
Spine & $17(4)$ & $39(12)$ \\
Not specified & $1(<1)$ & $1(<1)$ \\
\hline
\end{tabular}

* Multi-site investigation.

$\dagger 25$ patients referred by paediatricians and others.

TABLE II - Reported annual cost (£) of magnetic resonance imaging service

\begin{tabular}{|c|c|c|c|c|}
\hline & $\begin{array}{l}\text { Coventry } \\
\text { (1989 prices) }\end{array}$ & $\begin{array}{l}\text { United Kingdom }{ }^{\star 15} \\
\text { (1988 prices) }\end{array}$ & $\begin{array}{c}\text { Perth } \\
\text { (1989 prices) }\end{array}$ & $\begin{array}{c}{\text { United States }{ }^{9}}^{9} \\
\text { (1990 prices) }\end{array}$ \\
\hline Field strength $(T)$ & $0 \cdot 5-1 \cdot 5$ & 0.5 & 1.5 & 0.97 \\
\hline Magnet type & Cryogenic & Cryogenic & Cryogenic & Cryogenic \\
\hline Annual No of examinations & 2250 & 2000 & 2189 & 3146 \\
\hline \multicolumn{5}{|l|}{ Capital costs: } \\
\hline Equipment (annual equivalent) & $881050(157830) \ddagger$ & $1041000(180000) \ddagger$ & Not available & Not available \\
\hline Accommodation (annual equivalent) & $228795(17898) \ddagger$ & $173500(12300) \ddagger$ & Not available & Not available \\
\hline Total annual equivalent & $175728 \ddagger$ & $192300 \ddagger$ & $333600 \$$ & $389520 \|$ \\
\hline \multicolumn{5}{|l|}{ Revenue costs: } \\
\hline Staffing & 105272 & 65400 & 146380 & 68110 9 \\
\hline Operating & 52452 & 35300 & 54140 & $90770 "$ \\
\hline Service and maintenance & 63419 & 66500 & 56910 & 85710 \\
\hline Total costs & 221143 & 167200 & 257430 & 244590 \\
\hline Total cost & 396871 & 359500 & 591030 & 634110 \\
\hline Direct cost/patient & 176.40 & 179.80 & 270.00 & 201.609 \\
\hline Indirect costs & 6350 & - & 51070 & 130630 \\
\hline
\end{tabular}

${ }^{\star}$ Cost modelled using figures from the National Hospital, Queen Square.

tAverage values for 45 imaging facilities.

†Assumes seven year equipment life, 25 year accommodation life at $6 \%$ discount rate.

Assumes five year equipment life, 10 year accommodation life, and straight line depreciation.

Assumes five year equipment life, 18 year accommodation life at $10 \%$ discount rate.

ๆProfessional billing (radiologists) not included, average §123.30/patient. planned if magnetic resonance imaging was not available, plus basic data on the patient including sex, age, and prognosis. Each report on the results of magnetic resonance imaging had a follow up questionnaire attached to measure the impact on diagnosis, diagnostic certainty, patient management, and confidence in management. The same consultant provided both sets of information to ensure consistency for variables such as diagnostic certainty. Non-responders were followed up and notified that no benefit would be assumed if the questionnaire was not returned. Finally, the radiologist performing each scan completed two questionnaires (prospective and retrospective) to identify the benefit of magnetic resonance imaging in locating, identifying, and determining the extent of the disease.

\section{PATIENT OUTCOMES}

Before their scan patients completed a health status questionnaire using the Rosser 29 state classification based on disability and distress; scores range from +1.00 for no disability or distress to a minimum of $-1 \cdot 49 .^{24} \mathrm{~A}$ follow up questionnaire was sent to al patients six months after the scan. Questionnaires were completed by a close relative for children or severely incapacitated patients.

\section{DIAGNOSTIC PATHWAY}

We studied the medical records of 158 of the 782 patients in detail. A sampling frame was used so that records were representative in terms of total requests per centre and level of use per consultant. Cases were limited to referrals in weeks $1-21$ and weeks $35-52$, to monitor changes over time. All investigations and procedures performed during the illness (or in the previous 12 months if the condition was chronic) and during the six weeks after the scan were determined. We calculated costs for each radiographic procedure using a cost modelling approach; several British sources (all including capital costs) were converted to 1989-90 prices and averaged to produce a representative cost (Trent region, personal communication). ${ }^{1525}$

\section{Results}

One in three scans were judged to show no abnormality. The majority of patients $(437(56 \%))$ were referred by neurologists. Table I shows the importance of spinal imaging for neurosurgery. Almost a fifth of patients were referred for multisite investigations (75 (23\%) in neurosurgery, $65(15 \%)$ in neurology), an important factor in a time related examination such as magnetic resonance imaging. Most scans were requested to confirm an existing diagnosis $(345,44 \%)$, or to exclude a suspected disease $(270,35 \%) ; 114(15 \%)$ were ordered to monitor a diagnosed condition. Most neurologists referred for the first two reasons $(90 \%$ of referrals), whereas neurosurgeons monitored recognised conditions more frequently (35\%). Consultants completed a request form for all the patients, the questionnaire on magnetic resonance imaging results was completed for $654(84 \%)$.

\section{COSTS OF MAGNETIC RESONANCE IMAGING}

Table II shows the annual cost of the Coventry service (1989-90 prices at a throughput of 2250 patients/year) with international comparisons; the average cost of scanning a patient in Coventry was $£ 176.40$ ( $£ 179.20$ including indirect costs). The high level of fixed costs (capital and maintenance) makes cost per patient sensitive to throughput. The Coventry capital cost figure includes upgrading of software but magnetic resonance imaging systems need to have hardware and software constantly upgraded to keep up with technological developments. Estimates of the cost 
of upgrading are as high as $£ 120000-£ 200000$ every three to five years. ${ }^{22}$ Table II does not include the cost of gadolinium-diethylenetriamine penta-acetic acid (DTPA) (intravenous contrast medium) as this was not available at the time of the study. If contrast media and upgrading hardware are included in the Coventry figure a further $£ 15.50-£ 38.50$ is added; bringing the final figure to $£ 206.20$ (average) per patient.

\section{PATIENT CHARACTERISTICS}

In all, 410 patients completed health status questionnaires. The average quality of life score at the time of the scan was 0.904 , which is lower than the 0.982 recorded in a 1988 survey of 390 West Midlands resident ${ }^{26}$ and that reported for 100 patients having cranial and spinal magnetic resonance imaging $(0.986$ and 0.942 respectively). ${ }^{16}$ This cannot be attributed to age weighting. The age and sex breakdown mirrors that in the United Kingdom as a whole, ${ }^{27}$ and the breakdown for all 936 patients imaged was similar to that reported for other patients having magnetic resonance imaging (table III). Over the six months after the

TABLE III-Age and sex of patients referred for magnetic resonance imaging

\begin{tabular}{|c|c|c|c|c|}
\hline \multirow[b]{2}{*}{$\begin{array}{l}\text { Age } \\
\text { (years) }\end{array}$} & \multicolumn{3}{|c|}{ West Midlands } & \multirow{2}{*}{$\begin{array}{l}\text { Australia }^{41} \\
\text { Both sexes } \\
(\mathrm{n}=16178)\end{array}$} \\
\hline & $\begin{array}{l}\text { Females } \\
(\mathrm{n}=511)\end{array}$ & $\underset{(n=420)}{\text { Males }}$ & $\begin{array}{c}\text { Both sexes } \\
(\mathbf{n}=936)\end{array}$ & \\
\hline 0 & & & $1(<1)$ & $1(<1)$ \\
\hline $1-9$ & $11(2)$ & $14(3)$ & $25(3)$ & $647(4)$ \\
\hline $10-19$ & $40(8)$ & $34(8)$ & $74(8)$ & $1617(10)$ \\
\hline $20-29$ & $67(13)$ & 49 (12) & $117(13)$ & $2427(15)$ \\
\hline $30-39$ & $103(20)$ & $80(19)$ & $183(20)$ & 3074 (19) \\
\hline $40-49$ & $132(26)$ & $92(22)$ & $225(24)$ & 3074 (19) \\
\hline $50-59$ & 94 (18) & $90(21)$ & $186(20)$ & $2264(14)$ \\
\hline $60-69$ & $44(9)$ & $50(12)$ & $94(10)$ & $1941(12)$ \\
\hline $70-79$ & $20(4)$ & $8(2)$ & $28(3)$ & $971(6)$ \\
\hline $80-89$ & & $3(<1)$ & $3(<1)$ & $162(1)$ \\
\hline
\end{tabular}

^Australia $49 \%$ female; Coventry $54 \%$ female

scan the quality of life score fell, with the average score decreasing by 0.059 to 0.845 . This was predicted by consultants at the time of referral (no change or don't know for $547(70 \%)$ patients, slight deterioration for $164(21 \%)$, and some improvement for $40(5 \%)$ ).

\section{REPORTED INCREASES IN ACCURACY}

The principal benefits predicted by radiologists were increased accuracy in identification (368 (47\%) scans), determining the extent $(110(14 \%))$, and location $(39(5 \%))$ of disease and other benefits $(23(3 \%))$; for $242(31 \%)$ scans no benefit was identified. Examination shows that when increased accuracy in assessing the extent of the disease was expected, radiologists reported $88 \%$ (97) of scans delivered this; when increased accuracy in location was predicted, $82 \%$ (32) of scans delivered this; but when improved identification was expected only $45 \%$ (166) of scan delivered this.

\section{IMPACT ON DIAGNOSIS}

A change in diagnosis was reported in 159 cases $(20 \%$ of referrals). In 107 the change was major, with a shift in categories; table IV gives the diagnoses before magnetic resonance imaging. Of those patients with unknown and "other, physical" diagnoses, 27 had the diagnosis changed after imaging. Nevertheless, the number of patients with an unknown diagnosis increased from 44 to 59 overall. Twelve patients with unknown diagnoses had their condition classified, but 27 with a provisional diagnosis were reclassified as having an unknown diagnosis after the scan. The overall number of patients with a diagnosis of "other, physical" did not change. Change in diagnosis was associated with an increase in diagnostic certainty; the mean value of the distribution rising from $66 \%$ to
TABLE IV - Diagnosis before magnetic resonance imaging

\begin{tabular}{lc}
\hline Diagnosis & No (\%) of patients \\
\hline Congenital & $76(10)$ \\
Infection & $19(2)$ \\
Traumatic & $43(5)$ \\
Demyelinative & $150(19)$ \\
Vascular & $45(6)$ \\
Tumour & $108(14)$ \\
Alcohol or drug & $3(<1)$ \\
Degenerative & $100(13)$ \\
Unknown & $44(6)$ \\
Other, physical & $51(7)$ \\
Other, psychological & $1(<1)$ \\
Missing & $142(18)$ \\
\hline Total & $782(100)$ \\
\hline
\end{tabular}

$87 \cdot 5 \%$ (excluding diagnosis unknown). In a further $236(30 \%)$ cases diagnostic confidence was increased.

\section{IMPACT ON PATIENT MANAGEMENT}

Changes in management were reported in 208 (27\%) cases. Eleven of 138 proposed operations were abandoned. Three procedures were deferred, three replaced by radiotherapy, and two patients were transferred to other surgeons or hospitals for surgery. In six cases the surgical approach was changed and in a further 11 it was made more precise. Twenty five myelograms, 21 computed tomograms, and three angiograms were abandoned. In a further 226 (29\%) cases confidence in planned management was 윽 increased. ${ }^{28}$ Table $\mathrm{V}$ shows the relation between the impact of magnetic resonance imaging on diagnosis and that on patient management; changes in the two were closely, but not exclusively, linked.

TABLE V-Impact of magnetic resonance imaging on patient management and diagnosis

\begin{tabular}{|c|c|c|c|}
\hline & \multicolumn{2}{|c|}{ Management altered } & \multirow[b]{2}{*}{ Total (No (\%)) } \\
\hline & No & Yes & \\
\hline \multicolumn{4}{|c|}{ Diagnosis altered: } \\
\hline No & 539 & 84 & $623(80)$ \\
\hline Yes & 35 & 124 & $159(20)$ \\
\hline Total $(\mathrm{No}(\%))$ & $574(73)$ & $208(27)$ & $782(100)$ \\
\hline
\end{tabular}

DIAGNOSTIC PATHWAYS AND INVESTIGATION COSTS

Analysis of the 158 diagnostic pathways identified 93 computed tomograms, nine angiograms, 28 myelograms, and 12 combination computed tomograms and myelograms taken before magnetic resonance imaging. There was no significant difference between patients referred early and late in the study, indicating that consultants did not change their diagnostic working as they became more familiar with magnetic resonance imaging. The cumulative cost of the radiographic $\mathrm{N}$ procedures was $£ 25979$ ( $£ 164.40 /$ patient) compared $D$ with an average $£ 206.20$ for magnetic resonance 을 imaging. In addition, there were 61 planned admis- N sions, primarily or exclusively for investigations, with an average length of stay of 6.5 days. Assuming average $\sigma$ neuroscience inpatient costs of $£ 119$ a day at 1989 prices for non-surgical cases, ${ }^{15}$ inpatient stays added $£ 298.60$ to the average investigation cost per referral. $\$$ Twelve computed tomograms, four angiograms, and ${ }_{T}$ three myelograms were carried out in the six weeks after imaging. The low level of myelography is indicative of effective displacement by magnetic resonance imaging.

\section{MARGINAL COSTS OF MAGNETIC RESONANCE IMAGING}

Some of the cost of magnetic resonance imaging should be offset by displacement of other investigations. In Coventry the average cost saving associated with displaced radiographic procedures was relatively small, calculated to be an average $£ 12.50$ per neuroscience referral. Inclusion of associated inpatient stay 
costs (based pro rata on investigation patterns before magnetic resonance imaging) increased this to $£ 30.70$ per case. Surgical savings were slightly higher. The average length of stay for a single surgical procedure in the sample was $19 \cdot 5$ days; assuming neuroscience inpatient costs of $£ 183$ per day at 1989 prices (including surgery costs), ${ }^{15}$ the 11 abandoned surgical procedures produced a further estimated saving of $£ 50.20$ per patient scanned. Overall the cost savings were an average $£ 80.90$ per patient.

\section{Discussion}

Our evaluation highlights the tensions between ensuring maximum clinical impact and minimising overall costs. To use magnetic resonance imaging most effectively in "a situation where restriction seems necessary" 29 it might be argued that patients need to be thoroughly investigated by conventional techniques before they are referred for magnetic resonance imaging. But by doing this some of the savings that could be realised through displacing these earlier procedures will be lost and the total costs of investigation may prove unnecessarily high. However, using magnetic resonance imaging too early in the diagnostic pathway may also not be cost effective if the most suitable patients are not correctly identified. In this instance effects on patient management will be less common and any consequent cost savings lower. It cannot be cost effective for expensive magnetic resonance imaging to be substituted for less expensive techniques if there is little or no difference in diagnostic efficacy unless there are sufficiently large benefits in patient safety or comfort.

We found that the diagnosis was altered in $20 \%$ of cases after magnetic resonance imaging. This is a similar level to that recently reported elsewhere in Britain. ${ }^{16}$ Management was changed in $27 \%$ of cases, lower than in the recent British study, ${ }^{16}$ but in a further $29 \%$ of cases confidence in management increased. We estimated that management changes reduced the cost of imaging from $£ 206.20$ (including contrast media and upgrading costs) to a marginal cost of $£ 125.30$ per patient. There was no indication that patients' quality of life improved after magnetic resonance imaging; this agrees with the other British study. ${ }^{16}$

The West Midlands population could support five magnetic resonance imaging units. ${ }^{29-31}$ If provided, the resulting marginal cost to the region would be about $£ 1.4$ million a year at $1989-90$ prices, assuming that similarly high effects on patient management are maintained in all centres and all specialties (for example, orthopaedics). In the service setting, therefore, it seems that although magnetic resonance imaging can improve diagnosis this is achieved only at a higher overall cost.

One possible strategy to improve cost effectiveness would be to reduce the use of other radiographic procedures in the run up to magnetic resonance imaging. The diagnostic pathway information shows that in the neurosciences magnetic resonance imaging was used as an add on test and that invasive procedures such as myelography and combined computed tomography and myelography were often used before magnetic resonance imaging. If half of these procedures had been displaced this would have reduced the marginal cost $(£ 125.30)$ by $£ 62.20$ per patient (including the cost of admission to hospital). However, this might result in a larger number of inappropriate patients having magnetic resonance imaging.

If the costs of investigating patients cannot be reduced sufficiently to make the marginal cost of magnetic resonance imaging zero and patients' quality of life is not improved, the question which next needs to be asked is: What additional benefits does magnetic resonance imaging provide in terms of diagnostic impact which might be set against these costs? One way of describing this is in terms of the marginal cost per diagnostic change ${ }^{28}$; this was calculated to be $£ 626$ (for a marginal magnetic resonance imaging cost of £125). Although 29 of these diagnostic changes were moves from a provisional diagnosis to diagnosis unknown, the overall increase in patients with unknown diagnosis $(5 \cdot 5 \%$ to $7 \cdot 5 \%)$ was substantially less than that reported in a recent study where magnetic resonance imaging was used as a first line diagnostic procedure (3\% to $27 \%)$. $^{15}$ This effect might therefore be limited by more extensive radiographic investigation before magnetic resonance imaging.

Even after implementing a series of controls (setting quotas, introducing a structured request form, and restricting referral to consultants) it has not proved possible to introduce a magnetic resonance imaging service for the neurosciences at zero cost. It is imperative for clinicians and managers to audit further use of this expensive imaging procedure, perhaps using a management systems approach.$^{32}$ Even if minimisation of costs is the prime objective systematic monitoring is required of the degree to which cost savings from changes in patient management are maximised and costs of other investigations used in the diagnostic pathway are minimised.

We thank the West Midlands Regional Health Services Research Committee for funding this work, the consultants in the hospitals served by the Coventry magnetic resonance imaging unit, and the radiologists in the unit.

1 Schersten T, Sisk JE, eds. An international view of magnetic resonance imagin and spectroscopy. Int $\mathcal{F}$ Technol Assess Health Care 1985;1(3). (Special issue.)

2 Department of Health and Social Security. Magnetic resonance imaginga replacement for the CT head scanner? London: DHSS, 1985. (Health equipment information No 141 .)

3 National Institutes of Health Consensus Development Conference. Magnetic resonance imaging. Magn Reson Med 1986;6:1-14.

4 MRI: What are its applications; what will it replace? Health Technology 1988;2:3-11.

5 Bydder G. MRI: present status and future perspectives. Br $\mathcal{F}$ Radiol 1988;61: 889-97.

6 National Health Technology Advisory Panel, Australian Institute of Health. MRI assessment program: consensus statement on clinical efficacy of MRI. Canberra: Institute of Health, 1988 .

7 Cherryman G. Cost of operating a nuclear magnetic resonance imaging system. BMF 1985;291:1437-8.

8 Bogatay LM. Financial analysis can facilitate the MRI acquisition decision. Hospital Topics 1987;39:12-4.

9 Evens RG, Evens RG Jr. Analysis of economics and use of MR imaging units in the United States in 1990.AfR 1991;157:603-7.

10 Cooper LS, Chalmers TC, McCally M, Berrier J, Sacks HS. The poor quality of early evaluations of magnetic resonance imaging. JAMA 1988;259: 3277-80.

11 Kent DL, Larson EB. Diagnostic technology assessments: problems and prospects. Ann Intern Med 1988;108:759-61.

12 Schuman WP, Hillman BJ, Friedman PJ, Rosenquist CJ, Stark DD. Early evaluation of MR imaging: worthless or worthwhile? AfR 1988;151:857-64.

13 Kent DL, Larson EB. Magnetic resonance imaging of the brain and spine: is clinical efficacy established after the first decade? Ann Intern Med 1988;108 clinical 24 .

14 Larson EB, Kent DL. The relevance of socioeconomic and health policy issues to clinical research: the case of MRI and neuroradiology. Int $\mathcal{F}$ Technol Assess Health Care 1989;5:195-206.

15 University of York, Centre for Health Economics. Economic evaluation of the clinical application of $M R$ imaging. York: Centre for Health Economics, 1990.

16 Dixon AK, Southern JP, Teale A, Freer CEL, Hall LD, Williams A, et al. Magnetic resonance imaging of the head and spine: effective for the clinician or the patient? BMF 1991;302:78-82.

17 Szczepura AK, Stilwell JA. Information for decision makers at hospita laboratory level. Soc Sci Med 1988;26:715-25.

18 Evens RG, Evens RG Jr. Economic and utilization analysis of MR imaging units in the United States in 1987. Radiology 1988;166:27-30.

19 Health and Public Policy Commitree, American College of Physicians. Magnetic resonance imaging of the brain and spine. Ann Intern Med 1988;108:474-6.

Panel, Australian Institute of Health. MRI assessment program: third interim report. Canberra: Institute of Health, 1989.

21 Szczepura AK, Fletcher J, Fitz-Patrick JD. An evaluation of the introduction of magnetic resonance imaging (MRI) in a UK service setting. Health of magnetic resonance imaging (MRI) in a UK service setting. Health No 1 .

22 National Health Technology Panel, Australian Institute of Health. MRI assessment programme: final report. Canberra: Institute of Health, 1990.

23 Fineberg HV, Bauman R, Sosman M. Computerised cranial tomography: effect on diagnostic and therapeutic plans. JAMA 1977;238:224-7.

24 Rosser R. Issues of measurement in the design of health indicators: a review In: Culyer AJ, ed. Health indicators. Oxford: Martin Robertson, 1983

25 Stilwell J. The costs of $x$ rays. Br $\mathcal{F}$ Radiol 1984;57:647-9. 
26 Gudex C, Kind P. The QALY toolkit. York: University of York, Centre for Health Economics, 1988. (Discussion paper No 38.)

27 Department of Health and Social Services. Health and personal social services statistics for England. London: HMSO, 1989.

28 Szczepura AK. Value-in-use of bacteriology diagnostic tests: utilisation and cost-utility. Warwick: Business School Research Bureau, 1990

29 National Health Technology Advisory Panel, Australian Institute of Health. Magnetic resonance imaging services. Canberra: Institute of Health, 1990
30 Durick AA, Phillips ML. Diffusion of an innovation: adoption of MRI. Radiol Technol 1988;59:239-341.

31 Pribyl S. Demand forecasting and targeting of MRI services. Appl Radiol 1988;17:29-32.

32 Roberts H. Outcomes and performance in health care. London: Public Finance Foundation, 1990. (Discussion paper 33.)

\title{
Intensified conventional insulin treatment and neuropsychological impairment
}

\author{
Per Reichard, Anders Britz, Urban Rosenqvist
}

\section{Abstract}

Objective-To assess whether intensified insulin treatment, with an increased frequency of hypoglycaemic episodes, leads to cognitive deterioration.

Design-Prospective randomised trial of intensified conventional treatment and standard treatment. Setting-Outpatient clinic for patients with insulin dependent diabetes.

Subjects-96 patients with insulin dependent diabetes, high blood glucose concentrations, and non-proliferative retinopathy were randomised to intensified conventional treatment $(n=44)$ or standard treatment $(n=52)$.

Main outcome measures-Glycated haemoglobin concentration (metabolic control); the number of hypoglycaemic episodes reported by patients at each visit; results of computerised neuropsychological tests performed at entry and after five years.

Results - Mean glycated haemoglobin concentration during the study was $7 \cdot 2 \%$ (SE $0 \cdot 1 \%$ ) with intensified conventional treatment and $8.7(0 \cdot 1 \%)$ with standard treatment $(\mathbf{p}<\mathbf{0 . 0 0 1})$. During five years $34(77 \%$, $95 \%$ confidence interval $53 \%$ to $100 \%)$ of the patients given intensified treatment and 29 $(56 \%, 36 \%$ to $75 \%)$ of the others had at least one episode of serious hypoglycaemia $(p<0.05)$. The intensified conventional treatment group had a mean of $1 \cdot 1$ episodes of serious hypoglycaemia per patient per year compared with 0.4 episodes in the standard treatment group. Results of the neuropsychological tests were similar in the two groups after five years.

Conclusions-Intensified conventional insulin treatment led to lower blood glucose concentrations and a higher frequency of hypoglycaemic episodes, but patients showed no signs of cognitive deterioration.

Medicine II,

Södersjukhuset, and

Stockholm County Council

Teaching Center for

Diabetes (LUCD)

Stockholm, Sweden

Per Reichard, MD,

Anders Britz, RN

Urban Rosenquist, MD

Correspondence to: Dr P Reichard, Department of Internal Medicine II, Södersjukhuset, s-118 83 Stockholm, Sweden.
TABLE I-Characteristics of diabetic patients given intensified conventional treatment and standard

\begin{tabular}{lccccc}
\hline Treatment group & $\begin{array}{c}\text { No } \\
\text { (male/female) }\end{array}$ & $\begin{array}{c}\text { Duration of } \\
\text { diabetes } \\
\text { (years) }\end{array}$ & $\begin{array}{c}\text { Age } \\
\text { (years) }\end{array}$ & $\begin{array}{c}\text { Insulin dose } \\
(\mathrm{IU} / \mathrm{kg})\end{array}$ & $\begin{array}{c}\text { Body mass index } \\
\left(\mathrm{kg} / \mathrm{m}^{2}\right)\end{array}$ \\
\hline Intensified conventional & $44(22 / 22)$ & $18 \cdot 0(1 \cdot 0)$ & $29 \cdot 5(1 \cdot 1)$ & $0 \cdot 73(0 \cdot 03)$ & $22 \cdot 5(0 \cdot 3)$ \\
Standard & $52(27 / 25)$ & $16 \cdot 1(0 \cdot 7)$ & $31 \cdot 6(1 \cdot 0)$ & $0 \cdot 75(0 \cdot 03)$ & $22 \cdot 8(0 \cdot 4)$
\end{tabular}
treatment at entry. Values are means $(S E)$ unless stated otherwis

To clarify the long term effects of episodic hypoglycaemia on the brain has been suggested as a major $\omega$ scientific task. ${ }^{6}$ We report the results of computerised 0 neuropsychological tests after five years in patients 3 randomised to intensified conventional insulin treat- $\omega$ ment or standard treatment.

\section{Patients and methods}

One hundred and two patients were selected for entry to the study, and after five years 96 patientso remained in the study. ${ }^{1}$ Five patients had died and one ${ }^{\supset}$ had moved away from Stockholm. The patients initially had insulin dependent diabetes, non-proliferative retinopathy, and unsatisfactory blood glucose control, $\stackrel{\mathbb{D}}{7}$ as already described.' They were randomised to intensified conventional treatment $\left(n=48\right.$ at entry and $44^{-}$ after five years) or standard treatment ( $n=54$ at entry $\vec{\oplus}$ and 52 after five years). The treatment regimens have been described. ${ }^{7}$ The groups were similar with regard 0 to sex distribution, age, duration of diabetes, insulin dose, body mass index (table I), smoking habits, alcohol consumption, and initial microvascular complications. ${ }^{17}$

After three years an effort was made to reduce glycated haemoglobin concentration below $9 \%$ in allo을 the patients given regular treatment as nephropathy had been shown to increase steeply with higher concentrations. ${ }^{8}$ Two patients receiving standard treatment could not participate in the neuropsychological tests after five years because of reduced visual acuity.

Glycated haemoglobin concentration (normal range $\frac{0}{7}$ $3 \cdot 9-5 \cdot 7 \%$ ) was measured as described previously 13 and the numbers of serious hypoglycaemic episodes 0 ? (during which the patient required help from someone else) and episodes of unconsciousness were carefully 윽 recorded and reported by the patients at each office $N$ visit. $^{12}$ The symptoms during hypoglycaemia were recorded at baseline and after five years and were categorised as either predominantly adrenergic or neuroglycopenic. ${ }^{29}$

ment of microvascular diabetic complications at the expense of increasing the frequency of serious hypoglycaemic episodes. ${ }^{1}$ After three years of intensified conventional treatment the hypoglycaemic episodes had not caused any permanent cortical dysfunction, ${ }^{2}$ although earlier studies found that patients with serious hypoglycaemia showed neuropsychological deficits. ${ }^{3-5}$ These studies, however, were either non-randomised or cross sectional and retrospective.

\section{NEUROLOGICAL EXAMINATIONS}

Motor and sensory nerve conduction velocities wereco analysed in the ulnar nerve. ${ }^{10}$ Vibration and thermal $\mathbb{\Phi}^{\mathbb{D}}$ thresholds were measured on the hand." 12 Examina-? tions were performed at entry to the study and after five $\frac{T}{3}$ years on the patient's dominant side and with his or her skin temperature well controlled.

\section{NEUROPSYCHOLOGICAL TESTS}

The automated psychological test system measures cerebral dysfunction by a battery of computerised neuropsychological tests. ${ }^{13-16}$ It works on an Apple $\mathrm{IL}_{0}$ microcomputer with a custom made keyboard. Each test was performed twice, two days apart to exclude training effects, the first time as an exercise. Only data from the second session were used for analysis. Each 